\title{
A Socio-Statistical Survey Conducted to Draw a Direct Proportionality between COVID-19 and Psychological Disorders
}

Oyindrila Basu

Fellow Directorate of Addiction and Research at IASR

\author{
*Correspondence author \\ Oyindrila Basu \\ Fellow Directorate of Addiction and Research at IASR \\ USA
}

Submitted : 30 May 2020 ; Published : 29 Jun 2020

\begin{abstract}
It's been decades that the world has seen a pandemic like the one we are in today. COVID-19 is one such global pandemic where all of the nightmares are coming true for mankind, to maintain order and stay safe, the only thing that we can do is stay at home. But enclosing ourselves also means that our work is paused; our lives seem to be punctuated. Moreover, the everyday myths and fake news on the media and internet are eating away the remaining self-confidence in human beings. Everyone is in panic; people don't know what to do; it's a rush situation where each day is bringing a new horror with it. With the virus spreading like locust storm and unemployment rate soaring high, survival is becoming difficult with normalcy. Governments are reporting new numbers each day, which doesn t help much to common men, but confirms their probable risk. With fear lurking around, people are getting diseased with hypertension. When the doors to Nature and outside world are closed, slowly, anxiety, depression and other such psychic disorders are affecting people. Psychological problems are on forever high when you have to secure your physical health from Corona virus. The paper attempts to study the proportionate relationship between Corona Virus and mental health disorders in people.
\end{abstract}

\section{Introduction}

As we are trying to accommodate with the changing circumstances during COVID-19, we have to cope with mental health issues. This is an alarming problem which is spreading its wings slowly within mankind. In simple words, COVID-19 is directly affecting people's minds. Locked inside homes for months, people are suffering from depression as they are being deprived and denied of social lives, financial conditions, comfort and communication.

In a recent KFF poll, nearly half (45\%) of adults in the United States reported that their mental health has been negatively impacted due to worry and stress over the virus. Social distancing and isolation are having their repercussions. Job loss and infection panic is giving rise to anxiety, hypertension and even sometimes hallucination. Negative effects on mental health are more prominent in elder people and children who are easily tired with a forced lockdown. Since for these groups, productive engagement of brain is minimized, (as most of elderly people are retired) focus is always on what the news are reporting and what the hearsay are. Children have been prohibited to schools, so they are no longer engaged in their major work. As a result, they are getting impatient, then bored and finally depressed.

Health specialists are worried that it won't be long before the nations will have to face challenges in restoring their citizens' mental sanity. Juvenile depression is showing its fangs among home-locked children. Aged people in every country are suffering in anxiety when they get to know that the virus is infecting aged people heavily.

Literature Review

Its been ages, that the world has seen such a pandemic situation like COVID-19. The Spanish flu of 1918-1919 is being a point of reference here because at that time, Spain was one country which never censored its reports. Psychiatric times reports "The Spanish flu proved to be peculiar for several reasons, most noteworthy of course due to the high morbidity (as many 500 million were infected) and mortality (around 50 million deaths)." Starting in the mid-1990s, Jeffrey Taubenberger, $\mathrm{MD}, \mathrm{PhD}$, and his team were able to carry out a sequence and phylogenetic analysis of 1918 influenza virus genes and 
identified it to be an $\mathrm{H} 1 \mathrm{~N} 1$ virus of avian origin. Until around 1970 , historical research about the pandemic had been virtually non-existent. Some novels and popular histories appeared over the decades, but it was Alfred Crosby's 1976 book Epidemic and Peace, 1918 (reissued in 1989 under the title America's Forgotten Pandemic: The Influenza of 1918) that paved the way for international research about the subject. One of the book's major achievements was to draw light upon the fact that the pandemic quickly disappeared from public discussion topics, soon after the disease was over.

Howard Markel "organizes common elements in the social experience of pandemic disease into narrative frameworks, thereby providing additional insights into legal and ethical issues in pandemic mitigation. He also describes a more specific application of historical data from the influenza pandemic of 1918-1920: evaluating the effectiveness of nonpharmaceutical interventions to reduce the transmission and impact of infectious disease," says NCBI while talking about Learning from Pandemic's past. Heymann's and Markel's workshop presentations were complemented by remarks from D.A. Henderson of the University of Pittsburgh Medical Center, leader of the quarter-century campaign by the World Health Organization to eradicate smallpox (Henderson, 1999). He had noted several points which had allowed small pox to be an easy eradication. The virus infected only humans; it wasn't infectious until a rash appeared. It mostly spread through face-to-face contact. Indeed eradication of smallpox was revolutionary as it had given rise to an awareness of vaccinations, a goal that was made successful by 1990 , when $80 \%$ of the world population could be vaccinated against infectious diseases.

But the Corona Virus pandemic is nowhere close to it, as each day, the virus is mutating itself or showing up an individual behavior that was earlier unknown, hence common vaccines do not work here. Finding a vaccine is getting more and more difficult when testing infected or non-infected is so limited than required.

\section{Method}

The paper aims to analyze the statistical reports which show a positive growth in the count of mental health disorders in people tied down with social distancing. By comparing the reported cases of drug abuse, depression and other mental health issues, in regular times with those being reported during Corona, we will be able to understand how the pandemic is showing a proportionate rise in mental health issues. We have also conducted a questionnaire on a sample of 100 people who are locked down during the pandemic and who are seriously following social-distancing, to assess their behavioral changes during this time.

Prior to the COVID-19 pandemic, nearly one in five of U.S. adults (47 million) reported having a mental illness in the past year, and over 11 million had a serious mental illness, which frequently affects brain functioning and regular day-to-day activities. Prevalence of depression and anxiety was also high: In 2017-2018, nearly 17 million adults and an additional 3 million adolescents had a major depressive episode in the past year. In 2018, nearly a third (32.5\%) of adults reported feeling worried, nervous, or anxious on a daily, weekly, or monthly basis. Deaths due to drug overdose have increased more than threefold over the past 19 years (from 6.1 deaths per 100,000 people in 1999 to 20.7 deaths per 100,000 people in 2018). In 2018 , over 48,000 Americans died by suicide, 2 and in 2017 2018 , over ten million adults (4.3\%) reported having serious thoughts of suicide in the past year; as reported by KFF. It is expected by professionals that these numbers will significantly charge up during COVID-19. More number of deaths will be caused due to depressional suicide than corona, if people are forced longer on stay-at-home policy.

In the Early April KFF Tracking Poll, conducted March 25-30, 2020 , we found that $47 \%$ of those sheltering in place reported negative mental health effects resulting from worry or stress related to coronavirus. This rate is significantly higher than the $37 \%$ among people who were not sheltering in place reporting negative mental health impacts from coronavirus. Of those sheltering in place, $21 \%$ reported a major negative impact on their mental health from stress and worry about coronavirus, compared to $13 \%$ of those not sheltering in place.

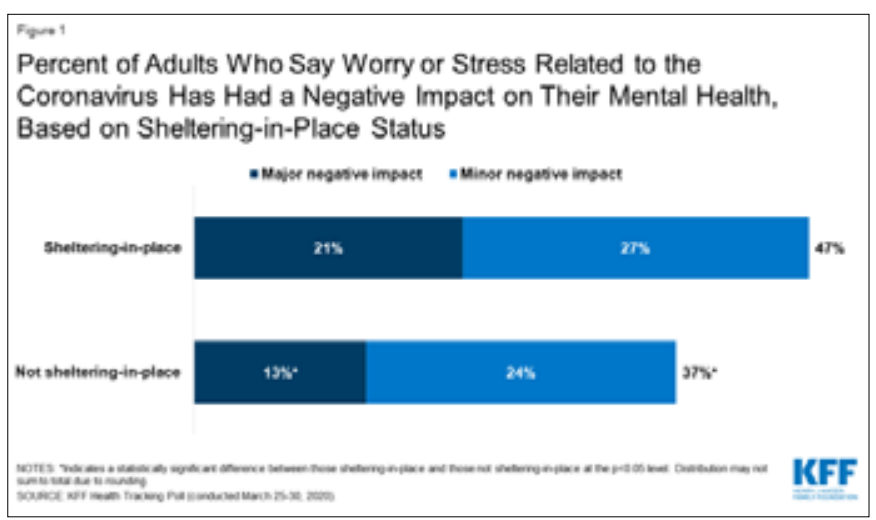

Graph source: KFF.org/coronavirus/covid-19

"A federal emergency hotline for people in emotional distress registered a more than 1,000 percent increase in April compared with the same time last year. Last month, roughly 20,000 people texted that hotline, run by the Substance Abuse and Mental Health Services Administration," reports Washington post. Talkspace has reported $65 \%$ rise in clients since late February. The text messages and therapy sessions provided by them were analyzed to find coronavirus related anxiety, dominating patients in these sessions.

We have conducted a therapeutic questionnaire on a sample of 100 people, 20 of whom are essential workers, like doctors, nurses, caregivers and the like, so they cannot maintain social distancing, but they are aware of the risks. One of them said, "I am not aware if I will be alive tomorrow; if I will be able to see tomorrow's sun; if I will see my children again; I am waiting for my turn but till I wait, I have to serve the people suffering with inhalation issues; I cannot see them gasping 
for breath." The statement clearly shows a negative impact on the person's mind. The fact that she is waiting for her death to arrive, the fact that she is unsure clarifies her anxiety. She shows symptoms of mild depression but she has not given up. $50 \%$ of the population reported that they wanted to break their doors, since they were behind those since four months now. Four of them were elderly people from India, aged between 60 and 70 years. They complained of their quarantined situation relentlessly; they felt their children did not care enough for them, as they work outside the state or country. They kept nagging on how they could not visit temples and perform their holy rituals because everything was closed; that they were feeling breathless indoors, they wanted to go out, they were waking up in fear every morning. They are worried that if they die in India, no one will know about it; no one will come for them. The statements are kind of self-centric but we can observe symptoms of hopelessness in them. Some people in the group were behaving like freaks with washing and cleaning so many times. "Every time we come inside the house, we start washing our hands and then washing the clothes; I make sure my husband dunks the packet of bread and milk in water after bringing them in", one of them responded. This was true for 10-12 people we communicated with; they were showing signs of obsessive-compulsive disorder.

This way, about $68-72 \%$ of people in the group were showing signs of some or the other kind of mental health issue, others showed slightly neurotic behavior based on the score of their questionnaire sheet.

\section{Discussion}

COVID-19 is an unusual situation for the Earth. While globally, we can observe a positive change in the environment; such that pollution levels are all time low; greenery is flourishing itself; biodiversity is finding peace in the form of wildlife and sea-life, we are also entrapped between a prominent danger which like a devil is eating away our soul, it is the corona virus. Everyday, the count of infected is rising, death rates are increasing, but another thing is increasing and that is poor mental health among people, especially old and young. Federal agencies and experts warn that a historic wave of mental-health problems is approaching: depression, substance abuse, post-traumatic stress disorder and suicide. Online counselling institutes and organizations are receiving all-time highest number of patients, mostly inflicted with anxiety and depression related to corona virus. Isolation is leading to loneliness; forced lockdown is breaking patience; lost jobs and unemployment are crushing the economy and self-confidence of individuals. It is clear that increase in mental health disorders is directly proportional to spread of corona.

\section{Conclusion}

It is a difficult time, but in order to survive, we must stand by each other. Yoga, meditation and mindfulness may sound cliched but they are absolutely necessary in moments of stress. Jogging and walking in the open maintaining social distancing can help cure the body and mind. As we sweat, our brain releases its dopamine which makes us feel good. Feeling positive is very important; eating healthy is equally important [1-5]. A good, healthy nutritious diet is always required in order to produce Vitamin B-12 which helps fight depression. Avoid too much carb or sugar. Avoid news channels and too much of exposure to social media. Engage yourself in a productive hobby like reading, writing, content making, cooking, music or anything with a positive vibe. Engaging the brain is the key to staying away from mental health issues during Covid-19.

\section{References}

1. Anonymous (2007) "Ethical and Legal Considerations in Mitigating Pandemic Disease", National Academy of Sciences, NCBI, 2007.

2. Anonymous (2020) "What Is Dopamine?", WebMD

3. Chidambaram Priya (2020) "The Implications of COVID-19 for Mental Health and Substance Use". KFF. org, 21st April 2020.

4. Eghigian Greg (2020) "The Spanish Flu Pandemic and Mental Health: A Historical Perspective", Psychiatric Times, May 28th 2020.

5. Wan William (2020) "The coronavirus pandemic is pushing America into a mental health crisis", Washington Post, May 4rth 2020.
Copyright: (C2020 Oyindrila Basu. This is an open-access article distributed under the terms of the Creative Commons Attribution License, which permits unrestricted use, distribution, and reproduction in any medium, provided the original author and source are credited. 